\title{
Aspectos clínico-patológicos da intoxicação experimental pelas sementes de Crotalaria mucronata (Fabaceae) em bovinos ${ }^{1}$
}

\author{
Murilo R. Boghossian ${ }^{2 *}$, Paulo V. Peixoto ${ }^{3}$, Marilene F. Brito ${ }^{4}$ \\ e Carlos Hubinger Tokarnia ${ }^{3}$
}

\begin{abstract}
Boghossian M.R., Peixoto P.V., Brito M.F. \& Tokarnia C.H. 2007. [Experimental poisoning by Crotalaria mucronata (Fabaceae) seeds in cattle.] Aspectos clínico-patológicos da intoxicação experimental pelas sementes de Crotalaria mucronata (Fabaceae) em bovinos. Pesquisa Veterinária Brasileira 27(4):149-156. Projeto Sanidade Animal Embrapa/UFRRJ, Seropédica, RJ 23890-000, Brazil. E-mail: mailto:mubogho@hotmail.com

Experiments were performed to define the clinical and pathological picture of prolonged administration of the seeds of Crotalaria mucronata Desv. to cattle, in order to obtain additional information about this toxicosis. The ground seeds were administered orally to 9 bovines. Doses of $1 \mathrm{~g} / \mathrm{kg} / \mathrm{day}, 2 \mathrm{~g} / \mathrm{kg} / \mathrm{day}, 3 \mathrm{~g} / \mathrm{kg} / \mathrm{day}$ each in one bovine, and $5 \mathrm{~g} / \mathrm{kg} /$ day in two of three bovines, given for 61- 63 days, did not cause poisoning. Doses of $5 \mathrm{~g} / \mathrm{kg}$, in one bovine, $7.5 \mathrm{~g} / \mathrm{kg}$ in two bovines and $10 \mathrm{~g} / \mathrm{kg}$ in one bovine, given for $47-61$ days, caused symptoms between 47 and 80 days after the first administration and caused death between 3 hours and 5 days after the onset of symptoms. The main clinical signs were positive venous pulse of the jugular vein, abdominal breath, tachycardia, loss of appetite, dry feces, sub-mandibular edema and weakness. Bovines that did not die, were slaughtered 8 or 9 months after first administration. At necropsy pulmonary paleness, hydropericardium, hydrothorax, hydroperitoneum, mesenteric edema, augmented hepatic consistency, discoloration of the liver, right cardiac ventricle dilatation and ruminal wall edema were seen. The main histological lesions were thickening of the alveolar walls and of the arterioles with narrowing of their lumen, and periarteriolar fibrosis, besides hepatic and cardiac lesions of minor importance. It is concluded, that the lesions caused by ingestion of the seeds of $C$. mucronata over a long period are caused by the difficulties of blood passage through the pulmonar vessels due to fibrosis and thickening of the arteriolar walls through the pneumotoxic action of the plant.
\end{abstract}

INDEX TERMS: Poisonous plants, Crotalaria mucronata, pyrrolizidine alkaloids, interstitial pneumonia.

RESUMO.- Sementes moídas de Crotalaria mucronata Desv. (=Crotalaria striata DC., Crotalaria pallida Ait., Crotalaria saltiana), com nomes populares de "xique-xique" ou "guizo-de-cascavel", foram administradas por via oral a 9 bovinos. As doses diárias

\footnotetext{
${ }^{1}$ Recebido em 6 de junho de 2006.

Aceito para publicação em 8 de dezembro de 2006.

Parte da dissertação de Mestrado do primeiro autor.

2 Programa de Pós-Graduação em Ciências Veterinárias da Universidade Federal Rural do Rio de Janeiro (UFRRJ). "Autor para correspondência: mailto:mubogho@hotmail.com

${ }^{3}$ Departamento de Nutrição Animal e Pastagem, Instituto de Zootecnia, Universidade Federal Rural do Rio de Janeiro (UFRRJ), Seropédica, RJ 23890000. E-mails: tokarnia@ufrrj.br, peixotop@ufrrj.br

${ }^{4}$ Departamento de Epidemiologia e Saúde Pública, Instituto de Veterinária, UFRRJ.
}

de $1 \mathrm{~g} / \mathrm{kg}, 2 \mathrm{~g} / \mathrm{kg}, 3 \mathrm{~g} / \mathrm{kg}$ cada uma a um bovino, e $5 \mathrm{~g} / \mathrm{kg}$ em dois de três bovinos, dadas durante 61 a 63 dias, não causaram intoxicação. A dose de $5 \mathrm{~g} / \mathrm{kg}$ em um bovino, $7,5 \mathrm{~g} / \mathrm{kg}$ em dois bovinos e $10 \mathrm{~g} / \mathrm{kg}$ em um bovino, dadas durante 47-61 dias, causaram sintomas entre 47 e 80 dias após o início da administração e a morte entre 3 horas e 5 dias após o início dos sintomas. Os principais sintomas foram pulso venoso positivo da veia jugular, respiração abdominal, taquicardia, inapetência, fezes ressequidas, edema sub-mandibular e fraqueza. Os achados de necropsia foram palidez pulmonar, hidropericárdio, hidrotórax, hidroperitôneo, edema de mesentério, aumento da consistência hepática, alterações de cor do fígado, dilatação de ventrículo cardíaco direito e edema da parede ruminal. As principais alterações histológicas concentraram-se nos pulmões, sob forma de espessamento das paredes alveolares e da parede das arteríolas com diminuição da luz e fibrose periarteriolar; ha- 
via também lesões hepáticas e cardíacas de menor importância. Pode-se concluir que as principais lesões causadas pela ingestão das sementes de $C$. mucronata durante períodos prolongados, devem-se à dificuldade de passagem do sangue pelos vasos pulmonares em função da hipertensão arterial decorrente de fibrose e espessamento arteriolar determinada pela ação pneumotóxica da planta.

TERMOS DE INDEXAÇÃO: Plantas tóxicas, Crotalaria muconata, pirrolizidinas, pneumonia intersticial.

\section{INTRODUÇÃO}

Plantas do gênero Crotalaria são conhecidas por "xique-xique", "guizo-de-cascavel" ou "chocalho-de-cascavel", pois os frutos, quando secos, produzem som semelhante ao de chocalho ao serem tocados. Também em função disso é que a planta recebeu o nome científico de Crotalaria, termo que em latim significa chocalho. No Brasil já foi registrada a ocorrência de, pelo menos, 40 espécies de Crotalaria. As espécies mais comuns são Crotalaria mucronata Desv. (= C. striata DC, C. pallida, C. saltiana, C. vitellina Kerr, C. anagyroides H.B.K. e C. retusa L. (Barroso 1974, Everist 1974, Tokarnia et al. 2000).

As crotalárias são importantes na agricultura pela capacidade de fixação de nitrogênio atmosférico no solo, por produzir húmus e fornecer cobertura vegetal para plantio direto, contudo quando ingeridas, podem intoxicar animais devido aos alcalóides pirrolizidínicos que encerram.

\section{Estudos efetuados no Brasil}

No Brasil só há um registro sobre a intoxicação espontânea por $C$. mucronata em bovinos. Em Minas Gerais, de um total de 1.300 , adoeceram 14 bovinos, dos quais 12 morreram. Estes animais receberam ração contaminada com sementes de Crotalaria mucronata e adicionalmente comeram a planta no quintal de uma casa abandonada. A evolução do quadro clínico foi de 15 a 30 dias. Necropsias realizadas em três bovinos revelaram lesões pulmonares e hepáticas. À microscopia, as lesões pulmonares eram caracterizadas por espessamento difuso das paredes alveolares devido à proliferação de pneumócitos do Tipo II e de fibroblastos. Em algumas áreas foram observados enfisema e dilatação dos espaços interlobulares. Em apenas um animal, o fígado apresentava áreas de necrose hemorrágica, principalmente na região ao redor da veia centro-lobular e moderada fibrose na região periportal. (Lemos et al. 1997, 1998)

A reprodução experimental da intoxicação por $C$. mucronata em bovinos foi realizada pela administração, via oral, das folhas recém-colhidas. Com doses únicas de 60 ou $80 \mathrm{~g} / \mathrm{kg}$ verificou-se um quadro agudo de intoxicação e morte. A dose de 25 $\mathrm{g} / \mathrm{kg}$, excepcionalmente, também causou a morte de um bovino. Doses únicas de $20 \mathrm{~g} / \mathrm{kg}$ não causaram alterações ou causaram somente sintomas leves. Em seis outros bovinos, que ingeriram as folhas em doses únicas de $25-40 \mathrm{~g} / \mathrm{kg}$, foram observados sintomas leves a moderados, passageiros. Os primeiros sintomas foram observados de 6-24 horas, contados do início da administração da planta. Nos casos fatais, a evolução da intoxicação foi de 4-44 horas, sobrevindo a morte em 16-68 horas após o início da administração da planta. Nesses casos, os sintomas mais evidentes foram tremores musculares; nos que sobreviveram observaram-se anorexia, focinho seco e fezes mais moles ou ressequidas, às vezes com muco. Os achados de necropsia nos dois bovinos que ingeriram 60 e $80 \mathrm{~g} / \mathrm{kg}$ foram negativos; no animal que ingeriu $25 \mathrm{~g} / \mathrm{kg}$ observaram-se hidrotórax e edema pulmonar acentuados. Os exames histológicos não revelaram alterações consistentes. Quando administradas repetidamente em pequenas quantidades (doses diárias de $2,5 \mathrm{~g} / \mathrm{kg}, 5 \mathrm{~g} / \mathrm{kg}$ ou $10 \mathrm{~g} / \mathrm{kg}$ durante 120,60 e 30 dias, sempre até completar $300 \mathrm{~g} / \mathrm{kg}$ ), as folhas frescas recémcolhidas não causaram sintomas de intoxicação. Também as inflorescências e as vagens verdes recém-colhidas, administradas de uma única vez, na dose de $60 \mathrm{~g} / \mathrm{kg}$, não provocaram sintomas de intoxicação. Pela dessecagem, as folhas perderam a maior parte da toxicidade. (Tokarnia \& Döbereiner 1982)

\section{Estudos realizados em outros países}

Em outros países, as informações sobre casos de intoxicação espontânea por Crotalaria mucronata em animais também são escassas e, na maioria, bastante vagas. Assim Hurst (1942) e Everist (1974) mencionam sem fornecer detalhes que C. striata tem sido acusada de intoxicar bovinos na Austrália; no Sudão a planta também tem sido acusada de causar intoxicações (Barri \& Adam 1981).

Somente encontramos um registro da intoxicação espontânea por $C$. mucronata; de 100 ovelhas transferidas para piquetes com grandes quantidades de $C$. mucronata, no sul de Queensland (Austrália), oito morreram duas semanas após terem sido transferidas. Após a inspeção do local foi observado que a planta tinha sido pastada pelos animais. Quatro dias depois outras 22 ovelhas morreram; os animais apresentaram ataxia nos membros posteriores, decúbito e morte em poucos minutos (sic). À necropsia havia grande quantidade de líquido de coloração amarelada, em parte coagulada, na cavidade torácica. (Laws 1968)

Em experimentos realizados na Austrália, as folhas frescas de $C$. striata em floração foram administradas à caprinos jovens. Duas a três onças $(56,7-85,0 \mathrm{~g})$ teriam sido suficientes para causar a morte em 24 horas; três onças teriam sido fatais dentro de oito horas. A morte ocorreu em 30-60 minutos após o aparecimento dos sintomas, caracterizados por andar cambaleante, incapacidade de ficar em pé, coma, pupilas dilatadas e morte. Os achados de necropsia foram intensa efusão pleural, congestão hepática e renal e inflamação do rúmen. A planta perdeu a toxicidade quando dessecada. (Lewis, de acordo com Hurst 1942)

Também na Austrália, as folhas frescas ou murchas de $C$. mucronata foram administradas a seis carneiros, por sonda esofágica. Doses únicas ao redor de $10 \mathrm{~g} / \mathrm{kg}$ levaram à morte quatro de cinco ovinos. Várias horas após terem recebido a planta, os animais mostraram dispnéia aguda e angústia e morreram dentro de poucos minutos. As principais lesões foram edema e congestão com hemorragias dos pulmões, hidrotórax e hidropericárdio. Exames histopatológicos revelaram, no pulmão, edema, congestão e hemorragias em alguns alvéolos; não foram constatadas lesões nas paredes dos vasos sanguíneos do pul- 
mão. Análises bioquímicas do sangue e plasma, não definiram o efeito da toxina. Um sexto carneiro, que recebeu a dose diária de 20/kg durante 120 dias, não adoeceu; sacrificado, foram verificadas leves lesões hepáticas, sob a forma de variação do tamanho dos hepatócitos e de seus núcleos. (Laws 1968)

No Sudão, seis bovinos, divididos em três grupos de dois, receberam as folhas frescas picadas de $C$. saltiana, através de sonda esofágica, diariamente, até o óbito ou a eutanásia, nas doses de $10 \mathrm{~g} / \mathrm{kg}, 5 \mathrm{~g} / \mathrm{kg}$ e $1 \mathrm{~g} / \mathrm{kg}$. Todos os animais mostraram inapetência, andar cambaleante, dispnéia, estado nutricional ruim e decúbito. Os bovinos que ingeriram $10 \mathrm{~g} / \mathrm{kg} / \mathrm{dia}$ e $5 \mathrm{~g} / \mathrm{kg} /$ dia morreram entre 6 e 40 dias; um que ingeriu $1 \mathrm{~g} / \mathrm{kg} / \mathrm{dia}$ morreu no $263^{\circ}$ dia, o outro foi sacrificado no $311^{\circ}$ dia do experimento. Os achados de necropsia, em todos os bezerros, foram hemorragias e congestão dos pulmões, fígado e rins. Nos bezerros que ingeriram $1 \mathrm{~g} / \mathrm{kg} / \mathrm{dia}$ havia ainda fibrose focal no fígado, o coração era flácido e havia hidroperitôneo e hidrotórax. Os exames histopatológicos revelaram, em todos os bezerros, congestão hepática, e nos bezerros que ingeriram $1 \mathrm{~g} / \mathrm{kg} / \mathrm{dia}$, fibrose portal e cariomegalia no fígado. Os exames laboratoriais revelaram queda nos valores das proteínas séricas e elevação nos valores de aspartato aminotransferase (AST) e amônia, em decorrência do dano hepático. As bilirrubinas não estavam alteradas. (Barri \& Adam 1981)

Também no Sudão, foram administradas a doze cabritos, folhas de $C$. saltiana, picadas e misturadas com água, via sonda esofágica. A três cabritos foram administradas doses diárias de $10 \mathrm{~g} / \mathrm{kg}$, a dois $5 \mathrm{~g} / \mathrm{kg}$, a dois $1 \mathrm{~g} / \mathrm{kg}$ e a três cabritos $0,5 \mathrm{~g} / \mathrm{kg}$, até a morte. Todos os cabritos apresentaram depressão, inapetência, dispnéia, dorso arqueado, perda de peso, desvio lateral da cabeça e do pescoço e decúbito. Os animais morreram entre o $7^{\circ} \mathrm{e}$ $46^{\circ}$ do experimento; quanto maior a dose ingerida, menor o tempo de sobrevivência. Os achados de necropsia foram congestão e hemorragias dos pulmões, rim e fígado. Nos caprinos que ingeriram 5 e $10 \mathrm{~g} / \mathrm{kg} / \mathrm{dia}$ foram vistos ainda enfisema pulmonar, edema das dobras do abomaso e enterite catarral. Nos caprinos que ingeriram 0.5 e $1 \mathrm{~g} / \mathrm{kg} / \mathrm{dia}$, o fígado era focalmente fibrótico, o coração estava flácido e a cavidade torácica continha líquido cor de palha. Os exames histopatológicos revelaram fibrose portal. Nos exames laboratoriais foram encontrados queda nos valores das proteínas séricas, elevação nos valores de AST e de amônia, em decorrência da falha dos hepatócitos em remover a amônia do sangue. As bilirrubinas, alanina aminotransferase (ALT) e fosfatase alcalina não estavam alteradas. (Barri et al. 1984)

Em trabalho anterior não se conseguiu estabelecer a natureza da intoxicação por $C$. mucronata (Tokarnia \& Döbereiner 1982). Dessa forma, esse estudo teve como objetivo estabelecer a patogênese e complementar as informações concernentes à intoxicação por essa planta em bovinos. Dada a baixa toxidez, optou-se por utilizarem-se as sementes.

\section{MATERIAL E MÉTODOS}

Foram utilizados dez bovinos, de ambos os sexos, sem raça definida, adultos jovens, com peso variando de103-160kg; um desses animais foi escolhido como controle. Os animais foram mantidos em baias individuais de alvenaria e uma vez ao dia eram soltos em área cercada.

Os animais foram adaptados ao local, vermifugados e vacinados contra raiva e clostridioses; receberam capim elefante (Pennisetum purpureum) picado, misturado com concentrado protéico para bovinos em crescimento. No período de estiagem, o volumoso de capim elefante foi substituído por feno de coast cross (Cynodon spp.).

As sementes de Crotalaria mucronata Desv. (fam. Fabaceae) (Fig.1) utilizadas no experimento eram moídas uma vez por semana. Quantidades previamente determinadas da semente moída eram oferecidas no cocho ou administgradas manualmente por via oral, caso os animais não as ingerissem espontaneamente. As doses diárias variaram de $1 \mathrm{a} 10 \mathrm{~g} / \mathrm{kg}$ por um período aproximado de 60 dias. Caso o animal adoecesse antes dos 60 dias, a administração era interrompida. Semanalmente os animais eram pesados e examinados com observação de parâmetros como motilidade ruminal, freqüências cardíaca e respiratória, temperatura retal e cor das mucosas visíveis. Quando o animal começava a demonstrar sintomas, os exames eram intensificados, chegando-se ao acompanhamento contínuo; os que não apresentavam sintomas com evolução para morte foram sacrificados nove meses após o início da administração das sementes, com exceção de um, que foram sacrificados após oito meses.

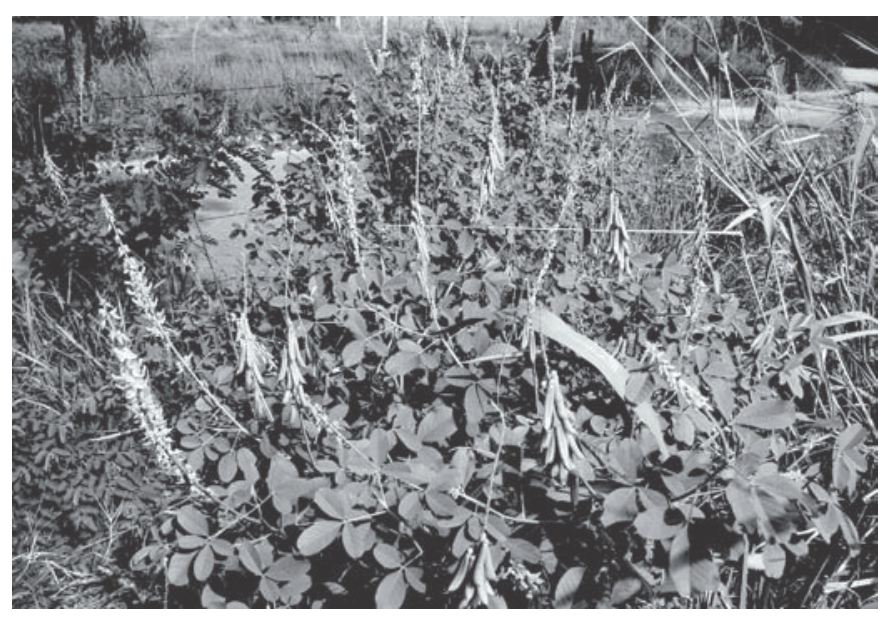

Fig.1. Crotalaria mucronata com inflorescências e vagens. Seropédica, RJ.

As necropsias foram realizadas logo após a morte dos animais; foram colhidos fragmentos de pulmão, coração, fígado, rim, linfonodos, baço, pâncreas, tireóide, adrenais, hipófise, diversas partes do trato digestivo, pele, músculos e sistema nervoso central, que foram fixados em solução de formol a $20 \%$, processados rotineiramente para histopatologia, cortados na espessura de $5 \mu$ e corados pela hematoxilina-eosina (HE). Cortes de pulmão e fígado foram corados pelo Tricrômico de Masson.

\section{RESULTADOS}

O delineamento experimental com os principais dados sobre a administração de sementes de Crotalaria. mucronata a bovinos, bem como sobre o desfecho, constam no Quadro 1.

\section{Sinais clínicos}

Sinais clínicos com evolução para morte natural ocorreram em quatro dos nove bovinos que receberam a planta.

O Bovino 5563 (5g/kg x 61 dias) diminuiu o consumo de ração aos 79 dias do experimento e 24 horas depois apresentou pulso venoso positivo com jugular bastante saliente (Fig.2), taquicardia, taquipnéia, corrimento mucoso nasal unilateral, 
Quadro 1. Delineamento experimental e desfecho na intoxicação experimental pelas sementes de Crotalaria mucronata em bovinos

\begin{tabular}{|c|c|c|c|c|c|c|c|c|c|c|c|}
\hline $\begin{array}{l}\text { Bovino } \mathrm{n}^{\circ} \\
\text { (mat. reg. } \\
\text { SAP) }\end{array}$ & $\begin{array}{l}\text { Pesoao iní- } \\
\text { cio do ex- } \\
\text { perimento }\end{array}$ & $\begin{array}{l}\text { Dose } \\
\mathrm{g} / \mathrm{kg} / \mathrm{dia}\end{array}$ & $\begin{array}{l}\text { Número } \\
\text { de admi- } \\
\text { nistrações }\end{array}$ & $\begin{array}{c}\text { Período de } \\
\text { administra- } \mathrm{n} \\
\text { s ção das se- } \mathrm{n} \\
\text { mentes }\end{array}$ & $\begin{array}{l}\text { Total de se- } \\
\text { mentes ad- } \\
\text { ministradas } \\
\quad(\mathrm{kg})\end{array}$ & $\begin{array}{l}\text { Total de se- } \\
\text { mentes ad- } \\
\text { ministradas } \\
\quad(\mathrm{g} / \mathrm{kg})\end{array}$ & $\begin{array}{l}\text { Intensi- } \\
\text { dade dos } \\
\text { sintomas }\end{array}$ & $\begin{array}{l}\text { Início dos sin- } \\
\text { tomas: data } \\
\text { e dias após o } \\
\text { início da ad- } \\
\text { ministração } \\
\text { das sementes }\end{array}$ & $\begin{array}{l}\text { Morte: data e dias após } \\
\text { o início da adminis- } \\
\text { tração das sementes }\end{array}$ & $\begin{array}{l}\text { Peso dos } \\
\text { bovinos } \\
\text { ao final } \\
\text { do expe- } \\
\text { rimento }\end{array}$ & $\begin{array}{l}\text { Duração } \\
\text { dos sin- } \\
\text { tomas }\end{array}$ \\
\hline $\begin{array}{c}5561 \\
(29914 / 15)\end{array}$ & 122 & 1 & 61 & $14.1-15.3 .03$ & 7,4 & 61 & $\mathrm{Ss}^{\mathrm{a}}$ & & $\begin{array}{c}\text { Eutanasiado em } 8.11 .03 \\
\text { ( } 9 \text { meses })\end{array}$ & 188 & \\
\hline $\begin{array}{c}5562 \\
(29916 / 17)\end{array}$ & 132 & 2 & 61 & 21.1-22.3.03 & 17,9 & 122 & Ss & & $\begin{array}{c}\text { Eutanasiado em } 15.11 .03 \\
(9 \text { meses })\end{array}$ & 195 & \\
\hline $\begin{array}{c}5563 \\
(29595 / 97)\end{array}$ & 103 & 5 & 61 & 21.1-22.3.03 & 34,9 & 305 & Morreu & $\begin{array}{c}10.4 .03 \\
\text { (80 dias) }\end{array}$ & 12.4.03(82 dias) & 122 & 48 horas \\
\hline $\begin{array}{c}5564 \\
(30608 / 27)\end{array}$ & & Controle & & & & & & & Eutanasiado em 30.7.05 & & \\
\hline $\begin{array}{c}5566 \\
(30331 / 34)\end{array}$ & 138 & 3,5 & 63 & $30.09-12.03$ & 32,5 & 220,5 & Ss & & $\begin{array}{c}\text { Eutanasiado em } 3.7 .4 \\
\text { (9 meses) }\end{array}$ & 200 & \\
\hline $\begin{array}{c}5567 \\
(30349 / 51 \mathrm{e} \\
30357 / 58)\end{array}$ & 144 & 5 & 62 & $27.10-27.12 .03$ & 348,4 & 310 & Ss & & $\begin{array}{c}\text { Eutanasiado em } 31.7 .04 \\
\text { (9 meses) }\end{array}$ & 207 & \\
\hline $\begin{array}{c}5568 \\
(30352 / 54 \text { e } \\
30359)\end{array}$ & 113 & 5 & 61 & $3.11 .03-3.1 .04$ & 37 & 305 & Ss & & $\begin{array}{c}\text { Eutanasiado em } 31.7 .04 \\
\text { (8 meses) }\end{array}$ & 161 & \\
\hline $\begin{array}{c}40 / 04 \\
(30369 / 70)\end{array}$ & 160 & 7,5 & 47 & $14.7-2.9 .04$ & 56,4 & 352,5 & Morreu & $\begin{array}{l}29.8 .04 \\
\text { (47 dias) }\end{array}$ & 29.8 .04 & & 3 horas \\
\hline $\begin{array}{c}5569 \\
(30435 / 37\end{array}$ & 105 & 7,5 & 60 & 10.11.04-8.1.05 & $5 \quad 58,9$ & 560,9 & Morreu & $\begin{array}{c}7.1 .05 \\
\text { (61 dias) }\end{array}$ & 9.1 .05 (61 dias) & 149 & 48 horas \\
\hline $\begin{array}{c}5570 \\
(30444 / 45\end{array}$ & 106 & 10 & 60 & 10.11.04-8.1.05 & $5 \quad 71,35$ & 600 & Morreu & $\begin{array}{l}26.1 . .05 \\
\text { (78 dias) }\end{array}$ & 31.1.05(83 dias) & 130 & 5 dias \\
\hline
\end{tabular}

a $\mathrm{Ss}=$ sem sintomas.

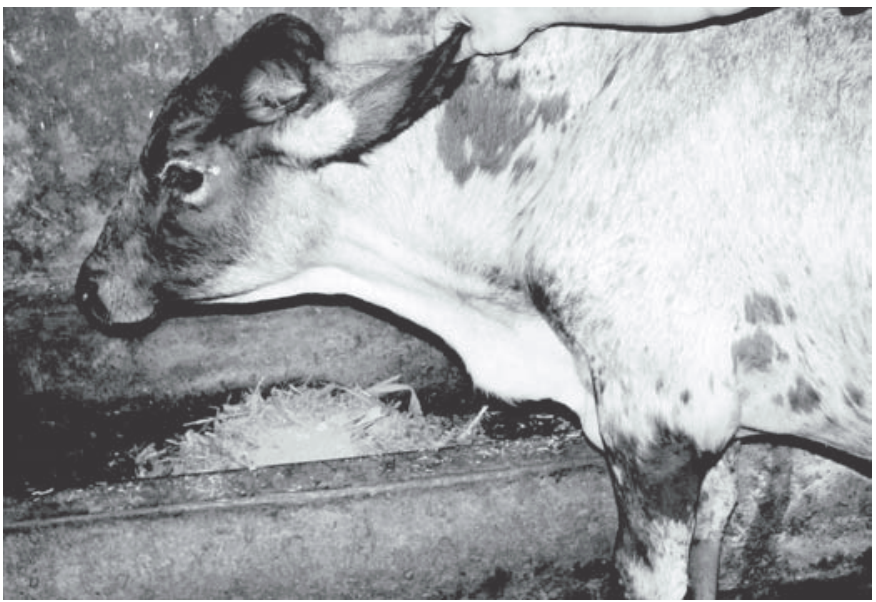

Fig. 2. Veia jugular ingurgitada, na intoxicação experimental por Crotalaria mucronata com dose de $5 \mathrm{~g} / \mathrm{kg} / \mathrm{dia}$ (Bovino 5563).

fezes ressequidas em pequenas cíbalas, dificuldade de se levantar, edema na parte inferior da barbela e extremidades frias. Esse animal ainda mostrou ranger de dentes, diminuição dos movimentos ruminais e, uma hora antes da morte, instabilidade dos membros posteriores, respiração ofegante e decúbito; a evolução clínica foi de 74 horas. O Bovino 40/04 (7,5 g/kg x 47 dias), às $18 \mathrm{~h} 00 \mathrm{~min}$ do $47^{\circ}$ dia do experimento, começou a se debater e morreu às $21 \mathrm{~h} 00 \mathrm{~min}$. Os sintomas observados no Bovino 5569 (7,5g/kg x 60 dias), à partir do $59^{\circ}$ dia do experimento, foram inapetência, pulso venoso positivo, hiperexcitação, taquicardia, taquipnéia com respiração abdominal, mucosas pálidas e opistótono. A evolução clínica foi de 48 horas. O Bovino 5570 (10g/ $\mathrm{kg}$ x 60 dias) começou, no $78^{\circ}$ dia do experimento, a apresentar pulso venoso positivo, decúbito externo-abdominal, taquicardia, fezes ressequidas em pequenas cíbalas e respiração abdominal, sintomas esses cada vez mais acentuados ao longo dos cinco dias de evolução até a morte. Dez minutos antes de morrer, o animal mostrou nistagmo, palidez das mucosas e midríase.

Sinais clínicos com recuperação espontânea ocorreram nos Bovinos 5567 e 5568; ambos receberam $5 \mathrm{~g} / \mathrm{kg}$ por 62 e 61 dias, respectivamente. Três meses e 15 dias após o término da administração, o Bovino 5567 evidenciou apatia e apetite reduzido por 48 horas. 0 Bovino 5568 mostrou, à partir de 46 dias após o término da administração, pulso venoso positivo ao longo de dois meses, antes de se recuperar.

\section{Achados de necropsia}

Os principais achados de necropsia constam no Quadro 2. (Fig.3-5)

\section{Alterações histológicas}

As principais lesões foram constatadas no pulmão e consistiram em espessamento da parede alveolar pela proliferação de células mesenquimais e fibrose intersticial (Fig.6), com infiltrados mononucleares e de eosinófilos, e, em três casos, proliferação de pneumócitos Tipo II (Fig.7). Também foram observados macrófagos em alvéolos fagocitando fibrina, macrófagos binucleados e hipertrofia de fibras musculares. Havia espessamento da parede das pequenas arteríolas pela proliferação de miócitos, presença de células mononucleares e fibrose 
(Fig.8), com diminuição do lúmen e fibrose periarteriolar. Nesses vasos, as fibras musculares evidenciaram sinais de ativação, com megalocitose, núcleos bizarros e/ou vesiculares.
No fígado verificaram-se congestão centrolobular e necrose coagulativa e, às vezes, lise de hepatócitos; em dois casos havia necrose centrolobular secundária à estase, nos

Quadro 2. Principais alterações macroscópicas na intoxicação experimental por sementes de Crotalaria mucronata em bovinos

\begin{tabular}{|c|c|c|c|c|c|c|c|c|c|c|c|c|}
\hline \multirow{2}{*}{$\begin{array}{l}\text { Bovino } \\
\text { no. }\end{array}$} & \multirow{2}{*}{$\begin{array}{l}\text { Dose } \\
\mathrm{g} / \mathrm{kg} / \mathrm{dia}\end{array}$} & \multicolumn{3}{|c|}{$\begin{array}{l}\text { Acúmulo de líquidos } \\
\text { em cavidades naturais }\end{array}$} & \multicolumn{4}{|c|}{ Edema } & \multicolumn{4}{|c|}{ Fígado } \\
\hline & & $\begin{array}{l}\text { Hidroperi- } \\
\text { cárdio }\end{array}$ & $\begin{array}{l}\text { Hidro- } \\
\text { tórax }\end{array}$ & $\begin{array}{l}\text { Hidrope- } \\
\text { ritôneo }\end{array}$ & Abomaso & Rúmen & $\begin{array}{l}\text { Vesícula } \\
\text { biliar }\end{array}$ & $\begin{array}{c}\text { Mesentério/ } \\
\text { omento }\end{array}$ & $\begin{array}{c}\text { Superfície } \\
\text { irregular }\end{array}$ & $\begin{array}{l}\text { Alterações de } \\
\text { consistência }\end{array}$ & $\begin{array}{l}\text { Evidenciação } \\
\text { da lobulação }\end{array}$ & $\begin{array}{c}\text { Alterações } \\
\text { da cor }\end{array}$ \\
\hline 5561 & 1 & & & & & & & & & & & $(+)^{a, b}$ \\
\hline 5562 & 2 & ++ & & + & & & & & & & & \\
\hline 5566 & 3,5 & & & & & & & & & & ++ & \\
\hline 5563 & 5 & + & + & ++ & & + & & +++ & & ++ & & $++c$ \\
\hline 5567 & 5 & & & & & & & & & $(+)$ & & \\
\hline 5568 & 5 & + & & + & & & & & & + & & \\
\hline $40 / 04$ & 7,5 & & & & & & +++ & $(+)$ & & & & \\
\hline 5569 & 7,5 & ++ & ++ & ++ & +++ & + & +++ & ++ & $+^{a}$ & & & $+d$ \\
\hline 5570 & 10 & +++ & + & +++ & +++ & + & +++ & +++ & + & & & +1 \\
\hline
\end{tabular}

$\bar{a}+++$ Lesão acentuada, ++ moderada, + leve, $(+)$ discreta.

b Pequenas estrias esbranquiçadas na superfície e ao corte do fígado.

c Fígado vermelho-azulado intercalando áreas mais escuras com áreas mais claras.

d Marrom claro levemente alaranjado.

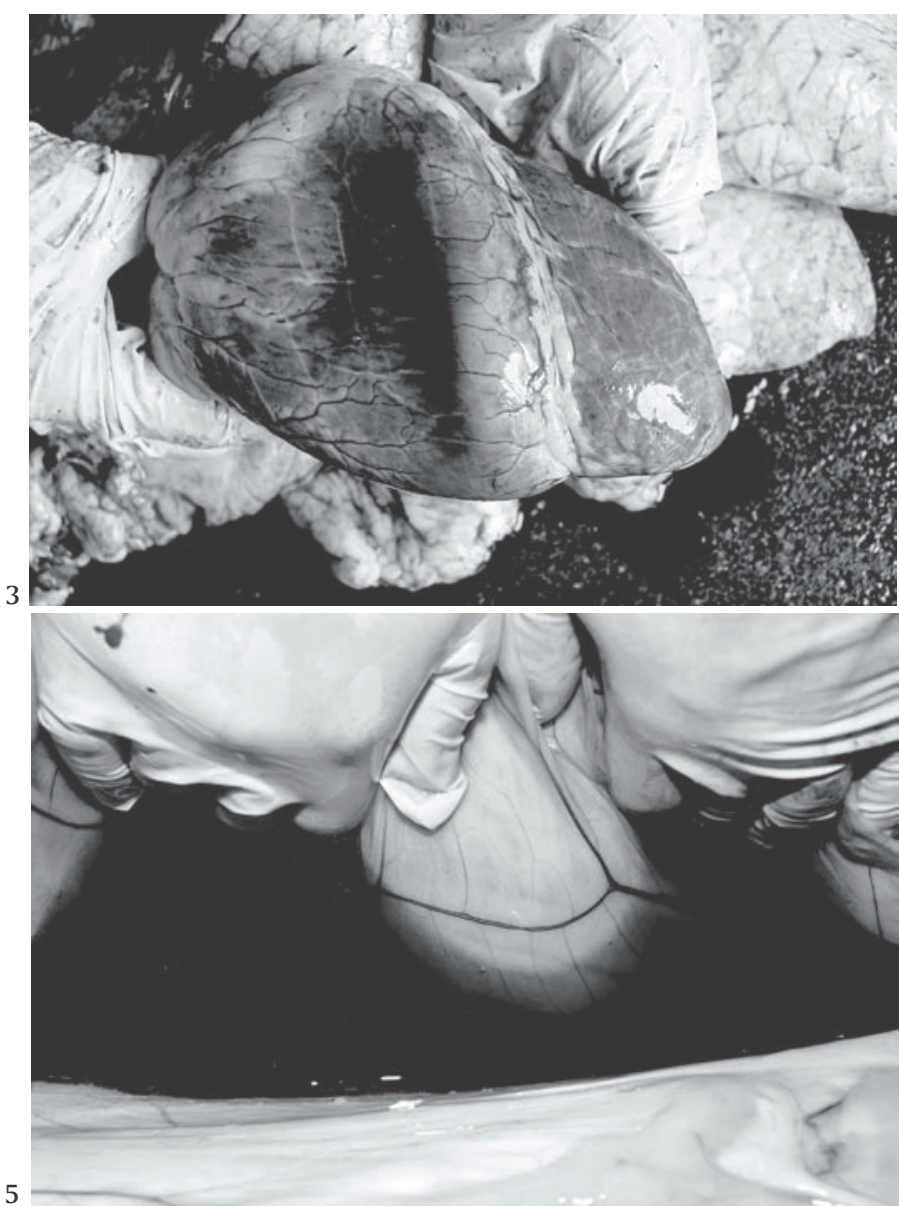

Fig.3. Saculação do ventrículo direito devido à dilatação, na intoxicação experimental por Crotalaria mucronata com dose de 7,5 g/ $\mathrm{kg} / \mathrm{dia}$ (Bovino 5569).

Fig. 5. Ascite, na intoxicação experimental por Crotalaria mucronata com dose de 10g/kg/dia (Bovino 5570).

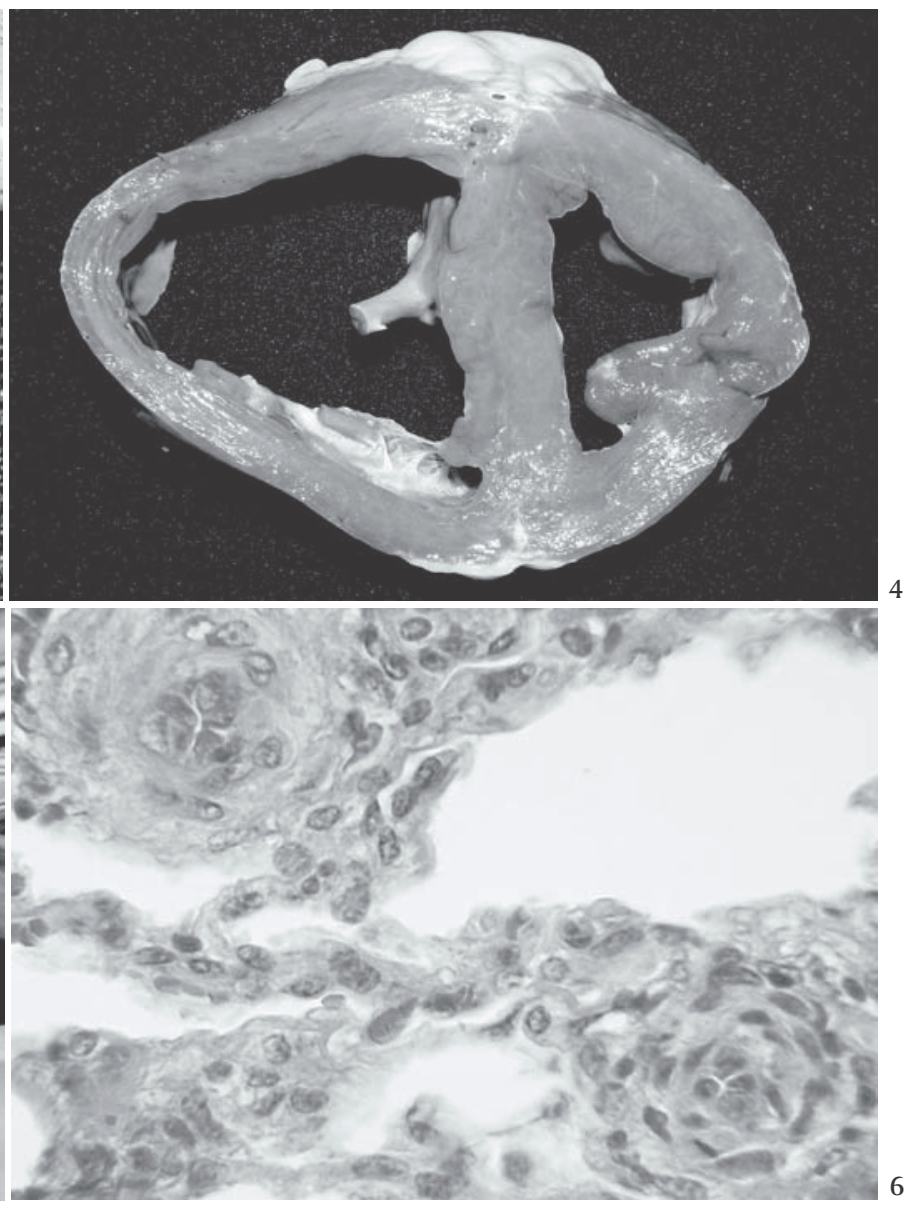

Fig.4. Dilatação da parede ventricular direta, na intoxicação experimental por Crotalaria mucronata com dose de $10 \mathrm{~g} / \mathrm{kg} / \mathrm{dia}$ (Bovino 5570).

Fig.6. Proliferação das células da parede alveolar de pulmão, na intoxicação experimental por Crotalaria mucronata do Bovino 5569 (SAP 30435). HE, obj.40. 

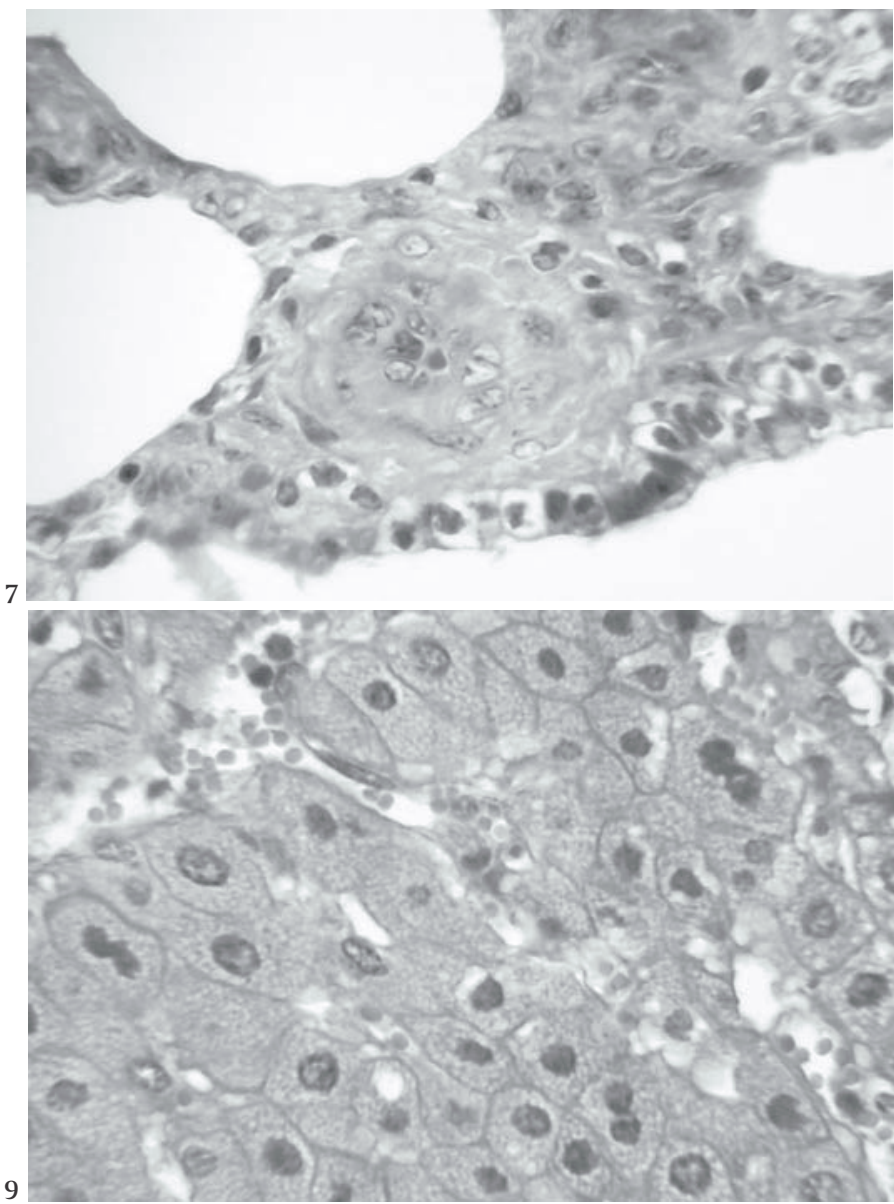

Fig.7. Espessamento da parede de pequena arteríola pela proliferação de miócitos e fibrose. Proliferação de pneumócitos Tipo II, na intoxicação experimental por Crotalaria mucronata do Bovino 5570 (SAP 30444). HE, obj.40.

Fig.9. Microvacuolização dos hepatócitos e três hepatócitos binucleados, na intoxicação experimental por Crotalaria mucronata do Bovino 5563 (SAP 29595). HE, obj.40.

dois outros a necrose era individual. Foi observado aspecto vítreo dos hepatócitos em dois casos e vacuolização citoplasmática (semelhante a que é descrita em casos de hiperplasia do retículo-endoplasmático liso, na ultramicroscopia) em quatro (Fig.9). Havia hepatócitos bi-ou trinucleados, outros com invaginação do núcleo, megalocitose e presença de "Councilman bodies". Foi verificado megalocitose das células de Kupffer (Fig.10) que, às vezes, tomavam aspecto bizarro, com núcleos indentados, gigantes, disformes, além de focos de eosinófilos dispersos no parênquima ou dentro dos sinusóides e edema do espaço de Disse (Fig.11).

No miocárdio foram observados miócitos grandes e com núcleos algo bizarros, "caterpillar cells" e miócitos com núcleos enfileirados ("Kernreihen”). Ainda constatou-se vacuolização de miócitos e pequenas áreas de necrose, congestão e edema.

Nos Quadros 3 a 5 constam com detalhes as alterações histológicas.

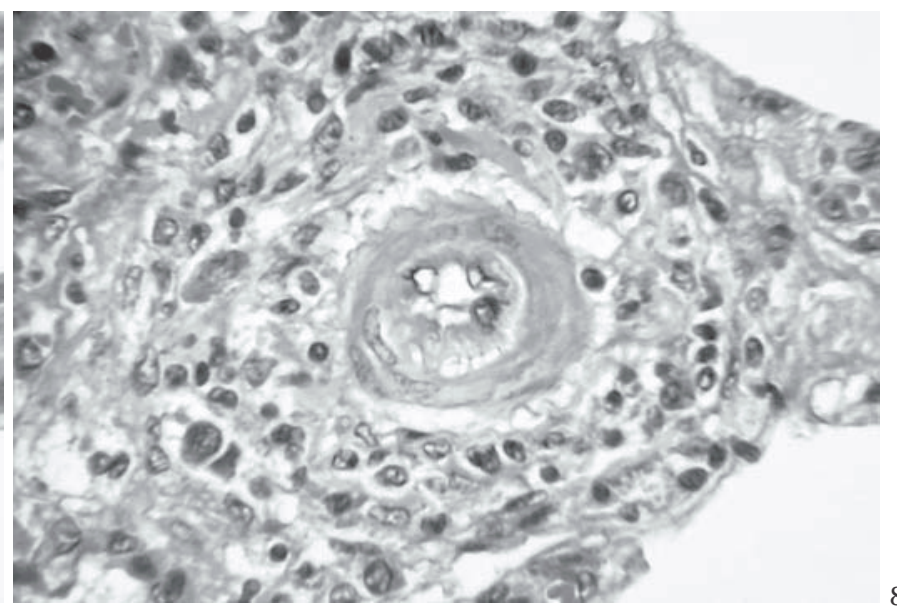

8

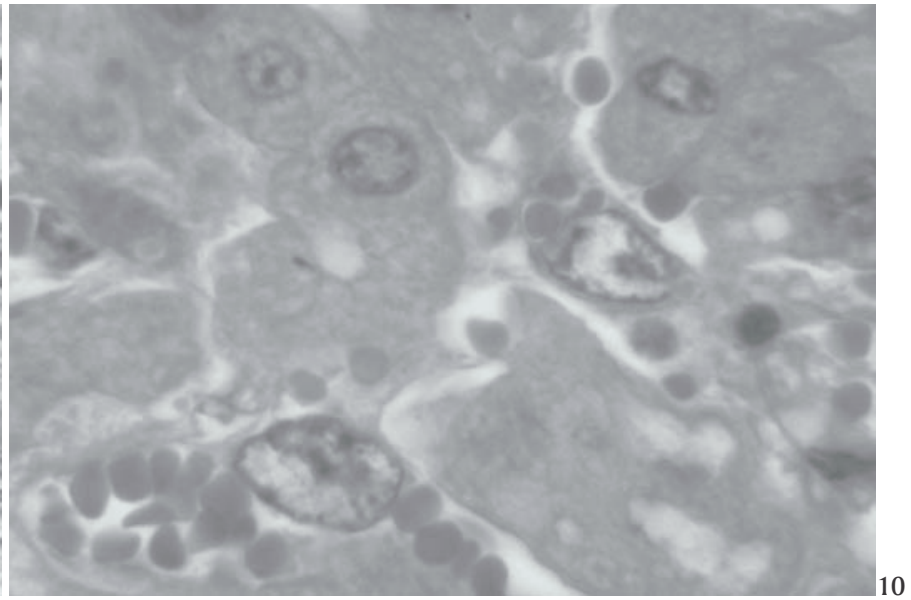

Fig.8. Periarteriolite com infiltrados monocitários, na intoxicação experimental por Crotalaria mucronata do Bovino 40/40 (SAP 30369). HE, obj.40.

Fig.10. Megalocitose das células de Kupffer, na intoxicação experimental por Crotalaria mucronata do Bovino 5570 (SAP 30444). HE, obj.100.

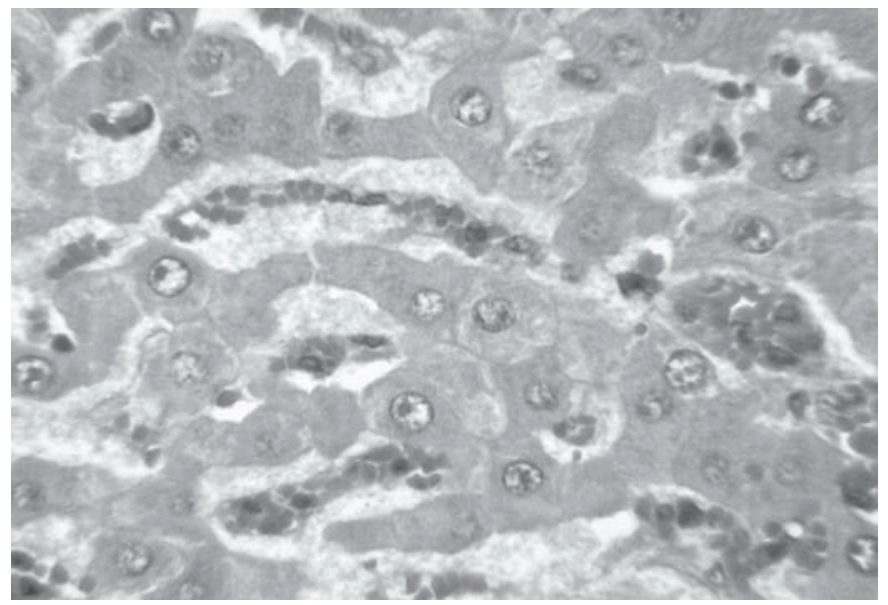

Fig.11. Fígado com edema do espaço de Disse, na intoxicação experimental por Crotalaria mucronata do Bovino 40/40 (SAP 30369). HE, obj.40. 
Quadro 3. Alterações histológicas no pulmão de bovinos na intoxicação experimental por Crotalaria mucronata

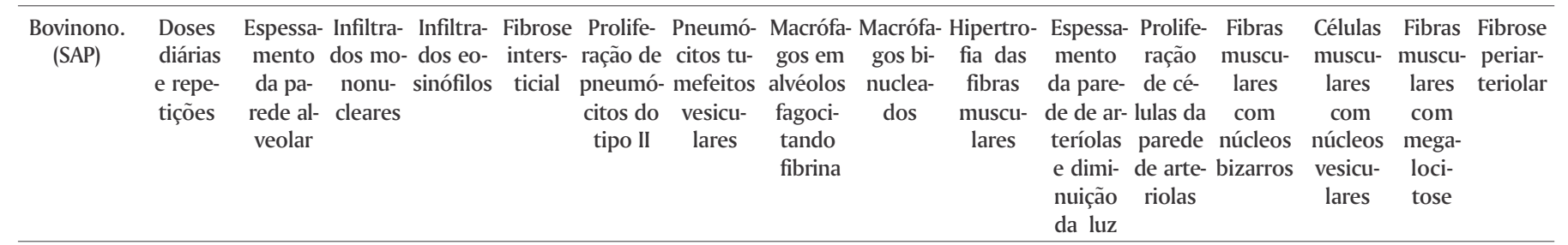

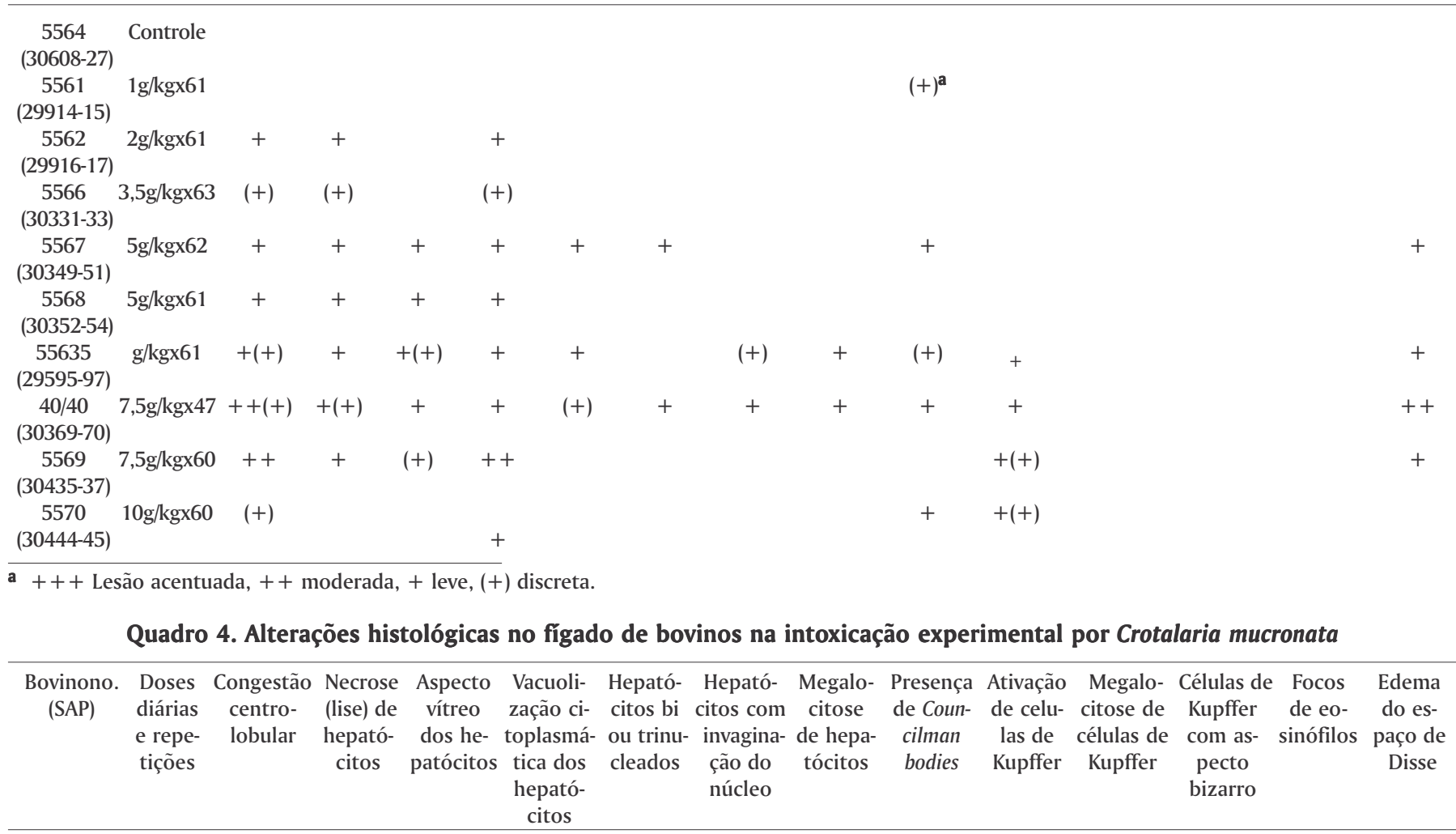

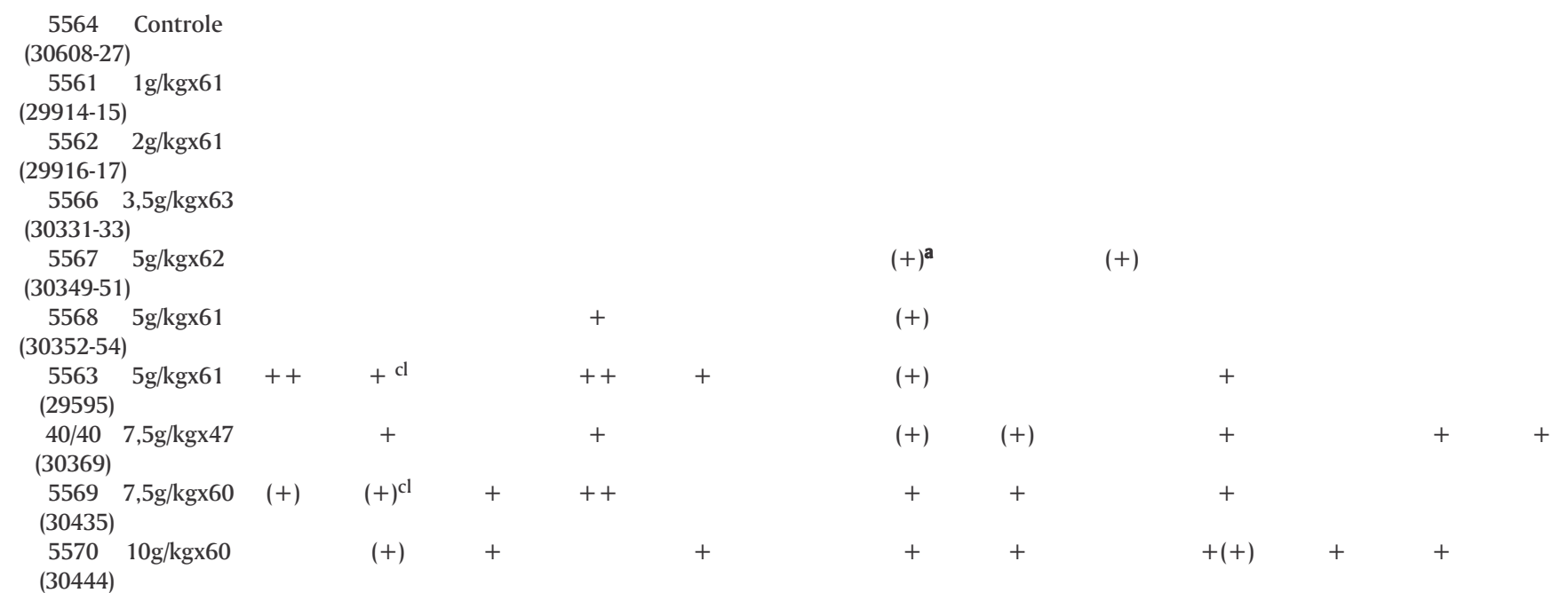

\footnotetext{
$\mathrm{a}=$ Lesão acentuada, ++ moderada, + leve, $(+)$ discreta, $\mathrm{cl}=$ centrolobular.
}

\section{DISCUSSÃO}

Esse estudo demonstrou que as sementes são mais tóxicas que as folhas de Crotalaria mucronata. O quadro clínico patológico, ao contrário do anteriormente verificado, foi bem de- finido por manifestações de insuficiência cardíaca (pulso venoso positivo), secundária às alterações pulmonares. Lesões cardíacas e hepáticas foram bem menos pronunciadas e devem ser consideradas como secundárias. 
Quadro 5. Alterações histológicas no miocárdio de bovinos na intoxicação experimental por Crotalaria mucronata

\begin{tabular}{|c|c|c|c|c|c|c|c|c|c|}
\hline $\begin{array}{l}\text { Bovinono. } \\
\text { (SAP) }\end{array}$ & $\begin{array}{l}\text { Doses diárias } \\
\text { e repetições }\end{array}$ & $\begin{array}{l}\text { Miócitos } \\
\text { grandes }\end{array}$ & $\begin{array}{l}\text { Miócitos com } \\
\text { núcleos bizarros }\end{array}$ & $\begin{array}{c}\text { "Caterpilar } \\
\text { cells" }\end{array}$ & $\begin{array}{l}\text { Miócitos com } \\
\text { núcleos en- } \\
\text { fileirados } \\
\text { (Kernreihen) }\end{array}$ & $\begin{array}{l}\text { Vacuolização } \\
\text { de miócitos }\end{array}$ & Necrose & Congestão & Edema \\
\hline $\begin{array}{c}5564 \\
(30608-27)\end{array}$ & Controle & & & & & & & & \\
\hline $\begin{array}{c}5561 \\
(29914-15)\end{array}$ & 1g/kgx61 & & & & $(+)^{a}$ & & & & \\
\hline $\begin{array}{c}5562 \\
(29916-17)\end{array}$ & 2g/kgx61 & & & & & & & & \\
\hline $\begin{array}{c}5566 \\
(30331-33)\end{array}$ & $3,5 \mathrm{~g} / \mathrm{kgx} 63$ & & & & & & & & \\
\hline $\begin{array}{c}5567 \\
(30349-51)\end{array}$ & $5 g / \operatorname{kgx} 62$ & & & & & & & & \\
\hline $\begin{array}{c}5568 \\
(30352-54)\end{array}$ & $5 g / \operatorname{kgx} 61$ & & & & + & & & & \\
\hline $\begin{array}{c}5563 \\
(29595-97)\end{array}$ & $5 g / \operatorname{kgx} 61$ & + & + & + & $+(+)$ & & & & \\
\hline $\begin{array}{c}40 / 40 \\
(30369-70)\end{array}$ & $7,5 \mathrm{~g} / \mathrm{kgx} 47$ & & + & + & + & + & + & $+(+)$ & $(+)$ \\
\hline $\begin{array}{c}5569 \\
(30435-37)\end{array}$ & $7,5 \mathrm{~g} / \mathrm{kgx} 60$ & & & & & & & & \\
\hline $\begin{array}{c}5570 \\
(30444-45)\end{array}$ & $10 \mathrm{~g} / \mathrm{kgx} 60$ & $(+)$ & $(+)$ & & + & & & & \\
\hline
\end{tabular}

Uma revisão da literatura (WHO 1988) mostra que, entre as plantas que contêm pirrolizidinas, Crotalaria spp. causam danos em vários tecidos na maioria das espécies animais. Algumas espécies de Crotalaria são pneumotóxicas para eqüinos, bovinos, ovinos e suínos, além de hepatotóxicas. Em suínos, sabe-se que as Crotalaria spp. são bastante nefrotóxicas. $C$. retusa, porém, constitui uma exceção; em eqüinos produz somente doença hepática (Nobre et al. 2004a,b).

Outras plantas, que contêm pirrolizidinas como Senecio spp., Heliotropium spp., Amsinckia spp. e Echium spp. são principalmente hepatotóxicas, contudo Senecio jacobaea é pneumotóxica para suínos, bem como para ratos e camundongos. Embora possa causar leve megalocitose renal na maioria das espécies animais, não há relatos de que $S$. jacobaea afete os pulmões de bovinos, ovinos, eqüinos ou aves.

Foi demonstrado, experimentalmente, que as pirrolizidinas pneumotóxicas causam hipertensão pulmonar associada à alterações vasculares nesse órgão. Estudos evidenciaram que a hipertrofia da média, tumefação e lise das células endoteliais, contribuem para o estreitamento da luz e espessamento da parede das artérias pulmonares com fibrose. $\mathrm{O}$ resultante aumento da pressão sangüínea arterial pulmonar leva à hipertrofia do ventrículo direito. (WHO 1988)

Ao que tudo indica, $C$. mucronata não representa grande risco aos bovinos, pois apesar de ser muito comun no Brasil, somente há um registro sobre a intoxicação natural em bovinos (Lemos et al. 1997); também em outros países, só há uma comunicação sólida da intoxicação por essa planta em ovinos, na Austrália.

\section{REFERÊNCIAS}

Barri M.E.S., Adam S.E.I. \& Omer O.H. 1984. Effects of Crotalaria saltiana on Nubian goats. Vet. Human Toxicol. 26(6):476-480.

Barri M.E.S. \& Adam S.E.I. 1981. The toxicity of Crotalaria saltiana to calves. J. Comp. Pathol. 91(4):621-627.

Barroso G.M. 1974. Comunicação pessoal (Jardim Botânico do Rio de Janeiro). Everist S.L. 1974. Poisonous Plants of Australia. Angus and Robertson Publishers, p.284-295.

Hurst E. 1942. The Poison Plants of New South Wales. N.S.W. Poison Plants Committee, Sydney, p.155-158.

Laws L. 1968. Toxicity of Crotalaria mucronata to sheep. Aust. Vet. J. 44(10):453455.

Lemos R.A.A., Dutra I.S., Souza G.F., Nakazato L. \& Barros C.S.L. 1997. Intoxicação espontânea por Crotalaria mucronata em bovinos em Minas Gerais. Arqs Inst. Biológico, São Paulo, 64(Supl.), Resumo 46.

Lemos R.A.A. \& Barros C.S.L. 1998. Intoxicação por Crotalaria sp., p.322-325. In: Lemos R.A.A. (ed.), Principais Enfermidades de Bovinos de Corte no Mato Grosso do Sul. Univ. Fed. Mato Grosso do Sul, Campo Grande, MS.

Nobre V.M.T., Riet-Correa F., Dantas A.F.M., Tabosa I.M., Medeiros R.M.T. \& Barbosa Filho J.M. 2004a. Intoxication by Crotalaria retusa in ruminants and equidae in the state of Paraiba, Northeastern Brazil, p.275-279. In: Acamovic T., Stewart C.S. \& Pennycott T.W. (ed.), Poisonous Plants and Related Toxins. CABI Publ., Wallingford, UK.

Nobre V.M., Riet-Correa F., Barbosa Filho J.M., Dantas A.F.M., Tabosa I.M. \& Vasconcelos J.S. 2004b. Intoxicação por Crotalaria retusa (Fabaceae) em equiídeos no semi-árido da Paraíba. Pesq.Vet.Bras. 24(3):132-143.

Tokarnia C.H. \& Döbereiner J. 1982. Intoxicação experimental por Crotalaria mucronata (Leg. Papilionoideae) em bovinos. Pesq.Vet.Bras. 2(2):77-85.

Tokarnia C.H., Döbereiner J. \& Peixoto P.V. 2000. Plantas Tóxicas do Brasil. Editora Helianthus, Rio de Janeiro.

WHO 1988. Pyrrolizidine Alkaloids: environmental health criteria. World Health Organization, Geneva. 